\title{
Reflexões sobre o potencial desconhecido do pagamento por serviços ambientais como instrumento para a gestão de mananciais hídricos urbanos
}

\author{
Reflections on the unknown potential of the payment \\ for environmental services as an instrument for urban \\ water resources management
}

Ana Paula Coelho Schimaleski [I] Carlos Mello Garcias [II]

\begin{abstract}
Resumo
Esta pesquisa busca analisar a potencialidade de sistemas de pagamentos por serviços ambientais (PSA) como um instrumento para a gestão de mananciais hídricos urbanos. A metodologia de pesquisa baseia-se essencialmente na elaboração de um cenário ideal com o PSA, buscando observar em que momento do tempo no processo de expansão urbana esse instrumento poderia ser aplicado de forma a contribuir para que o manancial não perdesse sua função essencial de fornecer água em quantidade e qualidade necessária à população. Conclui-se que o PSA pode ser um instrumento potencial para a gestão de mananciais hídricos urbanos, desde que seja adotado em sua concepção "holística" ou em conjunto com demais instrumentos que garantam a provisão de serviços ambientais relacionados aos recursos hídricos.
\end{abstract}

Palavras-chave: Pagamento por serviços ambientais; PSA; gestão de mananciais hídricos urbanos; gestão urbana; gestão ambiental urbana.

\begin{abstract}
This research aims to analyze the potential of systems of payments for environmental services (PES) as an instrument for urban water resources management. The research methodology is based essentially on the outline of an ideal scenario with PES, seeking to observe at what moment this instrument can be applied in the process of urban expansion, in order to help the water source not to lose its essential function of supplying water in appropriate quantity and quality to the population. It is concluded that PES can be an instrument for the management of urban water resources, provided it is adopted in its "holistic" conception or in conjunction with other instruments that guarantee the provision of environmental services related to water resources.
\end{abstract}

Keywords: payment for environmental services; urban water resources management; urban management; urban environmental management. 


\section{Introdução}

O Brasil é um país privilegiado em recursos hídricos. Detém aproximadamente $18 \%$ do potencial hídrico planetário, sendo o mais rico em recursos hídricos da Terra (FAO, 2003). Apesar desse cenário otimista, existem conflitos de quantidade (semiárido nordestino e regiões de uso intenso), qualidade e déficit de oferta (grandes capitais) (Andreoli et al., 2003, p. 43). No município de Curitiba e região metropolitana, por exemplo, a disponibilidade hídrica é restrita, mostrando a extrema importância de um cuidadoso planejamento do uso de seus mananciais. A deterioração dessas áreas força a busca por fontes mais distantes dos centros urbanos, o que pode acarretar um elevado custo operacional para acessar o recurso natural.

O Plano Diretor do Sistema de Abastecimento de Água Integrado de Curitiba e Região Metropolitana (Sanepar, 2013) apresenta a demanda que deverá ser atendida e os possíveis mananciais a serem utilizados. Alguns dos mananciais são desconsiderados devido à previsão de perda de qualidade da água, mas em nenhum momento são previstas medidas de recuperação e conservação dessas áreas, com vistas a atender à população futura. Isso evidencia uma postura insustentável, considerando a restrita disponibilidade de água e a piora constante dos mananciais de abastecimento para a metrópole. 0 problema da região metropolitana de Curitiba reflete-se também na realidade de outros centros urbanos brasileiros: a demanda por água tem aumentado e as atividades humanas causam a deterioração da qualidade de seus próprios mananciais.

Atualmente, diversos instrumentos são utilizados para a conservação de mananciais hídricos, como exemplo, a aplicação dos princípios poluidor-pagador (multas) e usuário-pagador (pagamento pelo uso da água). Outro instrumento que vem sendo utilizado e começa a apresentar resultados em alguns municípios brasileiros é o pagamento por serviços ambientais (PSA) ou pagamento por serviços ecossistêmicos, baseado no princípio provedor-recebedor. 0 termo serviços ambientais refere-se aos benefícios que os humanos obtêm dos ecossistemas e que são essenciais à manutenção da vida no planeta, satisfazendo as necessidades humanas materiais e não materiais (MEA, 2005, p. 49). Alguns dos principais serviços ambientais para o ser humano são aqueles relacionados a provisão e manutenção da água (purificação e regulação dos ciclos hídricos, controle de enchentes e erosão), porém a degradação dos ecossistemas tem resultado em uma perda de capacidade de ofertar tais serviços. O PSA surge, então, para dar incentivos econômicos àqueles que protegem os serviços oferecidos pelo meio ambiente, considerando que quem os utiliza deve suportar seus custos (Guedes e Sehusen, 2011, p. 34; Kfouri e Favero, 2011, p. 24).

Para que um programa de PSA possa existir, torna-se necessária uma condição: a existência de pelo menos um comprador e de, pelo menos, um provedor, sob a condição de que o provedor garanta a provisão de um serviço ambiental bem definido. Além disso, deve haver os indutores de sistemas de PSA, que podem ser de interesse voluntário, pagamentos mediados por governos ou regulamentação e acordos (Wunder, 2005, p. 3). No Brasil, atualmente, a Agência Nacional das Águas (ANA) gerencia o programa "Produtor de Água", que conta com diversos projetos de PSA relacionados a recursos hídricos. Até janeiro de 2020, 
existiam 27 projetos de produtores de água espalhados principalmente pelas regiões Sudeste, Centro-Oeste e Sul do Brasil.

A partir dessas considerações iniciais, esta pesquisa busca analisar a potencialidade de sistemas de pagamentos por serviços ambientais como instrumento para a gestão de mananciais hídricos urbanos, inserindo a recuperação e a conservação dos bens ambientais nas discussões referentes ao atendimento das demandas urbanas. Nesse sentido, a "potencialidade" refere-se à possibilidade que algo ou alguém tem de transformar a realidade.

Inicialmente, torna-se essencial esclarecer um conceito importante para esse trabaIho: o que é manancial hídrico urbano? Considera-se que o termo "manancial hídrico de bacia urbana" significa que ele esteja uma área urbanizada. Já para um "manancial hídrico urbano" entende-se todo e qualquer manancial cuja finalidade seja abastecer uma população urbana, não importando se está localizado em uma região rural ou urbana.

A metodologia da pesquisa baseia-se essencialmente na elaboração de um cenário ideal no qual haja o desenvolvimento de serviços ambientais essenciais a provisão e manutenção da qualidade da água, justificando, assim, possibilidades de existência do PSA: havendo o serviço/benefício pode haver o pagamento/valorização. Ressalta-se que não faz parte do âmbito deste trabalho analisar as características burocráticas de um sistema de PSA. Dessa forma, parte-se do pressuposto de que esse sistema terá todos os atributos e as características necessárias para que possa beneficiar a sociedade em geral. Buscar-se-á, além disso, observar em que momento do tempo, no processo de expansão urbana, esse instrumento pode ser aplicado de forma a contribuir para que um manancial não perca a sua função essencial de fornecer água em quantidade e qualidade necessária à população, ou seja, analisar o PSA como uma estrutura de controle (visando à conservação).

A observação dele como uma estrutura de controle contra a degradação ambiental poderá servir de base para a gestão de outros mananciais que ainda se encontram conservados, mas no limiar da degradação praticamente irrecuperável, causada pela urbanização inadequada e por usos degradantes do solo.

\section{0 pagamento por serviços ambientais como instrumento de gestão}

Em 2005, Wunder $(2005$, p. 3) definiu o PSA como uma transação voluntária na qual um serviço ambiental bem definido (ou um uso da terra capaz de assegurar esse serviço) é comprado por, no mínimo, um comprador de, no mínimo, um fornecedor, se, e somente se, o prestador assegurar a prestação do serviço ambiental (condicionalidade). Revendo esse conceito dez anos mais tarde, em 2015, após diferentes concepções utilizadas na literatura, Wunder $(2015$, p. 241) redefiniu o PSA como uma transação voluntária entre usuários de serviços e provedores de serviços que estão condicionados a regras acordadas de gestão dos recursos naturais para gerar serviços externos (relacionados às externalidades ambientais). Nota-se que, nessa nova definição, o "comprador" passa a ser chamado de "usuário do serviço" e o "vendedor" de "provedor do serviço", retirando os termos estritamente monetários. Ambas as definições estão relacionadas ao uso do solo 
e ao manejo dos recursos naturais de forma a promover o serviço ambiental, embora a definição recente ressalte 0 acordo de regras para a gestão dos recursos naturais. Neste trabalho, considerar-se-á a definição mais recente acrescida dos detalhamentos seguintes.

O PSA baseia-se no fato de que todo aquele que promove um serviço ambiental deve receber pela sua contribuição, a qual beneficia a sociedade (Figura 1). Ou seja, internalizar as externalidades positivas, enquanto os princípios de usuário-pagador e poluidor-pagador buscam internalizar as externalidades negativas (Engel, Pagiola e Wunder, 2008, p. 663).
Quando um sistema de PSA é aplicado para a gestão de mananciais hídricos, ele nada mais é que um incentivo recebido por um benefício gerado, ou seja, o produtor (geralmente rural) recebe uma quantia mensal em dinheiro em função da área de sua propriedade que está sendo preservada ou restaurada para a recuperação dos serviços ambientais, e a sociedade recebe em troca o aumento de quantidade e qualidade de água para seu abastecimento (Cidreira, 2016, p. 94). Cidreira (ibid. p. 95) ressalta que, para se alcançar a perfeita implementação de um PSA e ter uma eficiente gestão das águas urbanas, alguns critérios-base devem ser seguidos, sendo eles:

Figura 1 - Lógica dos sistemas de PSA

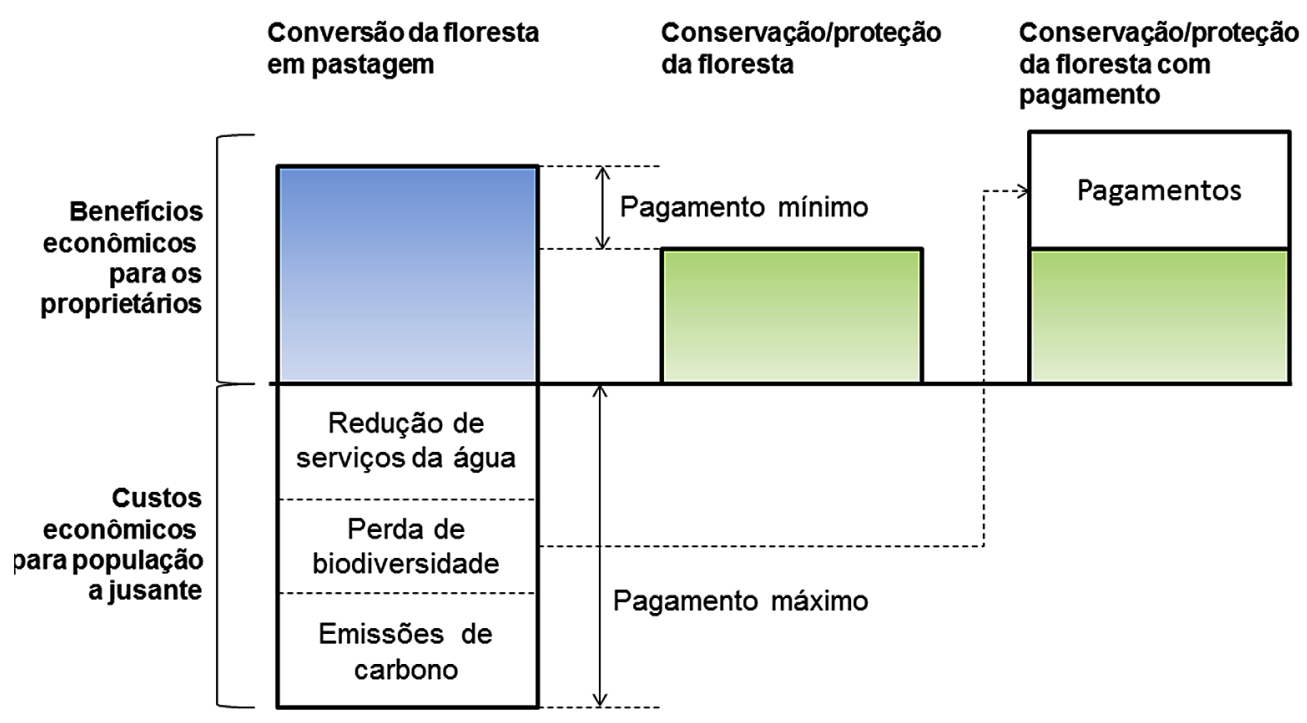

Fonte: adaptado de Engel, Pagiola e Wunder (2008, p. 663). 
a) o órgão provedor do sistema de PSA deve estar em dia com seus planos, conceitos e atividades ligadas ao meio ambiente, de maneira a dar exemplo nos assuntos relativos ao meio ambiente urbano e rural;

b) a inserção no programa, por meio dos produtores, deve acontecer de maneira voluntária e baseada em definições e cumprimento de metas preestabelecidas;

c) o programa a ser criado deve ser flexível com relação às práticas e aos manejos a serem propostos, propiciando, assim, maior aceitação pelos produtores;

d) o pagamento do produtor somente será realizado tendo como base o cumprimento das metas anteriormente estabelecidas;

e) devem ser estritamente respeitados os objetivos propostos para o programa; e

f) os pagamentos aos produtores devem ser honrados conforme contrato, de maneira a sempre beneficiar o produtor, fazendo-o lembrar da importância do seu ato, o qual deve ser recompensado adequadamente.

Como resultado de seu trabalho de pesquisa, Cidreira (ibid.) também apresenta o "guia de passo a passo para implementação de um sistema PSA". Ao todo são 15 passos essenciais para que um sistema possa funcionar de maneira a beneficiar a sociedade em geral (ibid., pp. 94-107):

1) adequar o município às questões ambientais;

2) escolher o modelo ideal de PSA;

3) identificar os parceiros e fontes;

4) instituir um marco legal;

5) obter um arranjo institucional;

6) definir a área de atuação e áreas prioritárias;

7) caracterizar os provedores dos serviços;

8) criar projetos executivos;
9) lançar a chamada para o programa e cadastramento inicial;

10) valorar os serviços ambientais e cálculos;

11) contratar o programa;

12) adequar as propriedades - recuperação das áreas degradadas e conservação;

13) pagar os produtores;

14) monitorar as propriedades;

15) criar ações de educação socioambiental. Altmann (2012) cita que o PSA clássico ou tradicional não foi pensado para áreas ou atividades urbanas. Esse instrumento foi originalmente criado para induzir agentes econômicos da área rural a adotar práticas de manejo e uso do solo ambientalmente sustentáveis. Entretanto, existem sistemas de PSA urbanos, pois as comunidades urbanas necessitam de serviços ambientais para o seu desenvolvimento, dependendo, como exemplo, de bens e serviços como água, controle do clima e umidade do ar, mitigação de efeitos das chuvas, entre outros. Dessa maneira, no meio urbano, ele pode estar relacionado à disposição correta de resíduos sólidos, mitigação da emissão de gases de efeito estufa, proteção das águas para uso urbano, manutenção de áreas verdes para a promoção da permeabilidade do solo, reduzindo risco de inundações urbanas, sendo uma ferramenta para mitigar ou evitar riscos à segurança da coletividade e ao meio ambiente (Tozzi, 2015).

No âmbito dos aspectos legais, o Brasil ainda não possui uma Política Nacional de PSA, mas essa concepção vem sendo considerada como um instrumento em outras políticas, tais como a lei de proteção da vegetação nativa, instituída pela lei federal n. 12.651/2012, que estabelece o PSA conforme o "programa de apoio e incentivo à preservação e recuperação 
do meio ambiente", em que uma das linhas de ação refere-se ao:

pagamento ou incentivo a serviços ambientais como retribuição, monetária ou não, às atividades de conservação e melhoria dos ecossistemas e que gerem serviços ambientais, tais como, isolada ou cumulativamente:

a) o sequestro, a conservação, a manutenção e o aumento do estoque e a diminuição do fluxo de carbono;

b) a conservação da beleza cênica natural;

c) a conservação da biodiversidade;

d) a conservação das águas e dos serviços hídricos;

e) a regulação do clima;

f) a valorização cultural e do conhecimento tradicional ecossistêmico;

g) a conservação e o melhoramento do solo;

h) a manutenção de Áreas de Preservação Permanente, de Reserva Legal e de uso restrito. (Brasil, 2012)

Além do pagamento ou do incentivo aos serviços ambientais, essa lei prevê, ainda, a compensação pelas medidas de conservação ambientais, tais como créditos agrícolas, redução do imposto sobre a propriedade rural (ITR), destinação de recursos arrecadados com a cobrança pelo uso da água para manutenção, recuperação ou recomposição de APPs e reserva legal, financiamento para atender iniciativas de preservação voluntária de vegetação nativa, entre outros. Até o momento apenas alguns municípios e estados brasileiros criaram legislações específicas e instituíram sistemas de pagamentos por serviços ambientais, caracterizando a sua pró-atividade, sendo o principal desafio para a efetivação do PSA a aprovação e implementação de uma política nacional (Mendes e Freiria, 2017).
A legislação brasileira implementa instrumentos econômicos na gestão ambiental. Por exemplo, a lei n. 6.938/1981 (Política Nacional de Meio Ambiente - PNMA) define a concessão florestal, a servidão ambiental, o seguro ambiental, entre outros, como instrumentos econômicos necessários à implantação da Política Nacional de Meio Ambiente. A lei n. 12.651/2012 (lei de vegetação nativa, comumente conhecida como novo Código Florestal), como já citada, define, como um de seus seis princípios, a criação e mobilização de incentivos econômicos para fomentar a preservação e a recuperação da vegetação nativa e para promover o desenvolvimento de atividades produtivas sustentáveis, entre eles o crédito de carbono. A Política Nacional de Resíduos Sólidos (lei n. 12.305/2010) busca internalizar as externalidades positivas, realizadas pelos catadores, que desempenham atividade de relevância ambiental, por meio da inserção de associações e cooperativas de catadores no processo. Tendo como base o princípio usuário-pagador, a Política Nacional de Recursos Hídricos (lei n. 9.433/1997) instituiu a cobrança pelo uso da água, atendendo ao estabelecido na PNMA, a qual estabelece a "imposição, ao poluidor e ao predador, da obrigação de recuperar e/ou indenizar os danos causados e, ao usuário, da contribuição pela utilização de recursos ambientais com fins econômicos".

Especificamente em relação ao PSA, está em trâmite no congresso nacional desde 2007 o projeto de lei (PL) 5.487/2009 que institui a Política Nacional dos Serviços Ambientais, o Programa Federal de Pagamento por Serviços Ambientais, e estabelece formas de controle e financiamento desse Programa. A revisão do Plano Nacional de Recursos Hídricos (período 2012-2015) estabelece, dentre as prioridades 
para esse período, o desenvolvimento de mecanismos de PSA, com foco na conservação de águas das bacias hidrográficas, além da recuperação e conservação de bacias hidrográficas em áreas urbanas e rurais (MMA, 2011). O plano considera que a continuidade dos serviços ambientais, essenciais à vida, depende diretamente da recuperação e da conservação ambiental, além de práticas que minimizem os impactos das ações humanas sobre o meio ambiente. Dessa forma, as recomendações referem-se ao apoio a projetos de conservação de águas, solo e vegetação por meio do PSA, e a avaliação continuada da implementação de tais programas em relação ao cumprimento de seus objetivos na gestão das águas. Como executores dessa prioridade, constam a Agência Nacional de Águas - ANA e o Ministério do Meio Ambiente - MMA (MMA, 2011, p. 53).

De acordo com levantamento feito por Cidreira (2016, p. 46), a origem do PSA deu-se nos Estados Unidos da América em meados de 1985, disseminando-se para outros locais do mundo. Em 1996, foi criado o Programa de PSA da Costa Rica e, em 1997, foi lançado o famoso Programa de Proteção de Mananciais da Cidade de Nova York. No Brasil, em 2001, foi criado o Programa Produtor de Água da Agência Nacional de Águas, mas foi a partir de 2005 que diversos programas brasileiros de PSA surgiram, motivados principalmente pelas questões de desenvolvimento de serviços ambientais relacionados aos recursos hídricos.

O primeiro exemplo de PSA no mundo foi o New York Watershed Protection Program (Programa de Proteção de Mananciais da Cidade de Nova York), nos Estados Unidos. Esse clássico e antigo exemplo refere-se aos serviços ambientais de provisão e manutenção da qualidade da água de sua bacia de manancial.
Na década de 1990, a cidade viu-se entre as opções de investir em um capital físico, com a construção de um sistema avançado de tratamento de água, ou na recuperação da integridade dos ecossistemas de Catskill, a bacia hidrográfica de onde provém a água de Nova York (Chichilnisky e Heal, 1998, p. 629). A primeira opção de investimento, em capital físico, teria um custo de 6 a 8 bilhões de dólares e de mais 300 milhões de dólares anualmente com manutenção do sistema. A segunda opção de investimento, em capital natural, que significa comprar e preservar terras ao redor dos mananciais e subsidiar a construção de melhores sistemas de tratamento de esgotos, teria um custo total de 1 a 1,5 bilhão de dólares. Dessa maneira, em 1996, a cidade de Nova York investiu esse valor em capital natural, esperando economizar um custo de 6 a 8 bilhões de dólares em 10 anos, tendo uma taxa interna de retorno de 90 a $170 \%$, em um período de retorno de 4 a 7 anos (ibid., p. 629).

No Brasil, um clássico exemplo de PSA também está relacionado a provisão e manutenção da qualidade da água e tem sido desenvolvido pela prefeitura municipal de Extrema/MG: o Projeto Conservador das Águas, com apoio do The Nature Conservancy do Brasil (TNC) e parceiros no município. Esse projeto foi reconhecido pela ONU como uma das melhores práticas mundiais de conservação. De acordo com esse Projeto, o produtor rural recebe, por ano, 175 reais/ha de área preservada que contribui para a provisão e manutenção da qualidade da água (Kfouri e Favero, 2011, p. 57). Atualmente a Agência Nacional das Águas gerencia o programa "Produtor de Água", que conta com diversos projetos de PSA relacionados aos recursos hídricos. Até janeiro de 2020, existiam 27 projetos de produtores 
de água espalhados principalmente pelas regiões Sudeste, Centro-Oeste e Sul do Brasil (ANA, 2020).

\section{Cenário ideal com o pagamento por serviços ambientais}

Para que um sistema de PSA seja possível, torna-se necessária a garantia do fornecimento de serviços ambientais: no caso desse trabaIho, os serviços de provisão (quantidade) e manutenção da qualidade da água. Os serviços de provisão de água estão relacionados ao ciclo hidrológico da bacia hidrográfica e dependem da precipitação, interceptação, escoamento superficial (detenção superficial), escoamento subsuperficial (água no solo) e escoamento de base (água subterrânea). Nesse processo, observa-se que a constância do fluxo hídrico superficial (quantidade de água) depende das características climáticas na bacia hidrográfica, do escoamento superficial, da infiltração da água no solo e recarga do lençol.

As características climáticas e de precipitação na bacia hidrográfica são variáveis externas e que não podem ser controladas no nível local com instrumentos de gestão, embora possam ser influenciadas pelas técnicas sustentáveis adotadas em níveis locais. Em relação à interceptação e ao escoamento superficial, observa-se que a água que escoa superficialmente pode ser interceptada por uma floresta, por uma área de agricultura, por uma área urbana ou por outras combinações. O escoamento superficial em uma área urbana, dependendo das características do sistema de drenagem, pode provocar efeitos de cheia (principalmente nas condições de drenagem convencional). Em uma área de agricultura, além dos efeitos de cheia devido à alta velocidade de escoamento, pode ocorrer o carreamento de sedimentos que provocam a erosão do solo e o assoreamento do corpo hídrico. Já, em uma área com floresta ou com a vegetação de mata ciliar preservada, o escoamento superficial pode ser interceptado e barrado, preservando o corpo hídrico contra os efeitos de cheia e assoreamento.

O escoamento subsuperficial e o de base também são verificados de diferentes formas entre os ambientes urbanos, de agricultura e de floresta. No ambiente urbano, a infiltração no solo é mínima (dependendo das condições de drenagem), e a água precipitada é praticamente destinada, em sua totalidade, ao escoamento superficial, não havendo a recarga do solo e do lençol. Em menor intensidade, a mesma característica acontece em áreas cultivadas (agricultura), pois a remoção da vegetação natural dificulta a infiltração no solo e favorece o escoamento superficial. Já, em uma área de floresta, a diversidade da vegetação e as características do solo permitem maior infiltração devido a interceptação e redução da velocidade do escoamento superficial.

Os serviços de manutenção da qualidade da água (recurso hídrico superficial) também dependem da interceptação e do escoamento superficial. 0 escoamento superficial em uma área urbana pode carregar consigo a poluição difusa (sujeiras da área urbana, tais como resíduos sólidos, desgaste de freios automotivos, poluição do ar, entre outros). Em uma área de agricultura ou com solo descoberto, sedimentos decorrentes de processos erosivos e agrotóxicos (incluídos como poluição difusa) também podem ser carreados ao corpo hídrico. Já, 
em uma área com floresta ou com a vegetação de mata ciliar preservada, tais poluentes encontram maior barreira para chegar ao corpo hídrico. Dessa forma, esses serviços de manutenção estão relacionados à qualidade da água que chega ao rio principal e à capacidade de autodepuração natural, estando relacionada ao uso do solo da bacia hidrográfica; entre os componentes condicionantes, consta o nível dos serviços de saneamento básico e limpeza pública, o tipo de culturas desenvolvidas (com foco no uso de agrotóxicos), além dos demais componentes condicionantes já citados para os serviços de provisão.

Com base nessas considerações, foram selecionados cinco componentes condicionantes para que os serviços de provisão e manutenção da qualidade da água sejam mantidos constantes: conservação da vegetação ciliar e demais áreas de preservação permanente (APPs), controle da taxa de impermeabilização do solo, desenvolvimento de técnicas de

Quadro 1 - Componentes condicionantes para o desenvolvimento dos serviços ambientais de provisão e manutenção da qualidade da água

\begin{tabular}{|c|c|c|c|}
\hline $\begin{array}{c}\text { Componentes } \\
\text { condicionantes/ Serviço } \\
\text { Ambiental }\end{array}$ & Parâmetro limite & Função ambiental & Técnicas adotadas \\
\hline $\begin{array}{l}1 \text { - Conservação da } \\
\text { vegetação ciliar e demais } \\
\text { APPs / PA e QA }\end{array}$ & $\begin{array}{l}\text { Atendimento à lei de } \\
\text { vegetação nativa (lei n. } \\
\text { 12.651/2012) }\end{array}$ & $\begin{array}{l}\text { - Escoamento superficial - redução da } \\
\text { velocidade } \\
\text { - Escoamento subsuperficial - } \\
\text { infiltração da água e recarga do lençol } \\
\text { - Ambiente urbano e rural - controle } \\
\text { da poluição difusa } \\
\text { - Equilíbrio do ecossistema }\end{array}$ & $\begin{array}{l}\text { - Recuperação de APPs } \\
\text { - Criação de unidades de conservação, } \\
\text { tais como corredores ecológicos e } \\
\text { parques municipais, unindo as APPs } \\
\text { com demais áreas verdes a serem } \\
\text { conservadas }\end{array}$ \\
\hline $\begin{array}{l}2 \text { - Controle da taxa de } \\
\text { impermeabilização do } \\
\text { solo / PA e QA }\end{array}$ & $\begin{array}{l}\text { Taxa máxima de } \\
\text { impermeabilização: } 35 \%\end{array}$ & $\begin{array}{l}\text { - Escoamento subsuperficial - } \\
\text { infiltração da água e recarga do lençol } \\
\text { - Escoamento superficial - redução da } \\
\text { velocidade }\end{array}$ & $\begin{array}{l}\text { - Preservação e ocupação de áreas } \\
\text { verdes municipais } \\
\text { - Limites à impermeabilização dos } \\
\text { terrenos em áreas urbanas (definição } \\
\text { de índice) }\end{array}$ \\
\hline $\begin{array}{l}3 \text { - Desenvolvimento de } \\
\text { técnicas de agricultura } \\
\text { e pecuária menos } \\
\text { ofensivas/PA e QA }\end{array}$ & $\begin{array}{l}\text { Todas as áreas agrícolas } \\
\text { devem seguir as técnicas } \\
\text { adotadas }\end{array}$ & $\begin{array}{l}\text { - Ambiente rural - controle da } \\
\text { poluição difusa }\end{array}$ & $\begin{array}{l}\text { - Agricultura orgânica } \\
\text { - Sistemas agroflorestais }\end{array}$ \\
\hline $\begin{array}{l}4 \text { - Aplicação de técnicas } \\
\text { de drenagem urbana } \\
\text { sustentáveis / PA e QA }\end{array}$ & $\begin{array}{l}\text { Toda a drenagem urbana } \\
\text { deve seguir pressupostos } \\
\text { da drenagem sustentável }\end{array}$ & $\begin{array}{l}\text { - Escoamento superficial - redução da } \\
\text { velocidade } \\
\text { - Escoamento subsuperficial - } \\
\text { infiltração da água e recarga do lençol } \\
\text { - Ambiente urbano - controle da } \\
\text { poluição difusa }\end{array}$ & $\begin{array}{l}\text { - Sistema integrado de drenagem } \\
\text { urbana sustentável: aproveitamento } \\
\text { da água da chuva, telhados verdes, } \\
\text { paredes verdes, controle no lote, } \\
\text { calçadas permeáveis, pavimento } \\
\text { poroso, valas de infiltração, wetlands, } \\
\text { bacias de retenção, bacias de } \\
\text { detenção, recarga do aquífero. }\end{array}$ \\
\hline $\begin{array}{l}5 \text { - Garantia de qualidade } \\
\text { dos serviços de } \\
\text { saneamento básico / QA }\end{array}$ & $\begin{array}{l}\text { Universalização do } \\
\text { serviço considerando as } \\
\text { técnicas adotadas }\end{array}$ & $\begin{array}{l}\text { - Ambiente urbano e rural - controle } \\
\text { da poluição pontual e difusa }\end{array}$ & $\begin{array}{l}\text { - Manejo de águas pluviais urbanas } \\
\text { - aplicação de técnicas de drenagem } \\
\text { urbana sustentáveis } \\
\text { - Limpeza urbana e manejo de } \\
\text { resíduos sólidos (coleta, tratamento e } \\
\text { destinação final) } \\
\text { - Abastecimento de água } \\
\text { - Esgotamento sanitário (coleta e } \\
\text { tratamento) }\end{array}$ \\
\hline
\end{tabular}

Legenda: * PA: serviços de provisão de água; QA: serviços de manutenção da qualidade da água. Fonte: os autores. 
agricultura e pecuária menos ofensivas, aplicação de técnicas sustentáveis de drenagem urbana e garantia de qualidade dos serviços de saneamento básico. Para cada componente foram definidos parâmetros limites e técnicas a serem adotados para a manutenção das funções ambientais importantes para os serviços ambientais estudados. 0 Quadro 1 demonstra os componentes condicionantes para o desenvolvimento dos serviços ambientais de provisão e manutenção da qualidade da água.

\section{Possibilidades de desenvolvimento ao longo do tempo: além do pagamento por serviços ambientais tradicional}

Provavelmente, a aplicação de um instrumento de PSA em um momento limiar no tempo que caracterize a provisão mínima de serviços ambientais poderia induzir à adoção de demais instrumentos e técnicas de conservação ambiental, como é o caso de agricultura e pecuária menos ofensivas (agricultura orgânica, sistemas agroflorestais), técnicas de drenagem urbana sustentáveis e garantia da qualidade dos serviços de saneamento básico. Em um contexto tradicional, a aplicação do PSA dá-se em áreas que não passaram pelo processo de urbanização, principalmente pelo processo irregular e pela expansão populacional. Um primeiro cenário de aplicação seria enquanto as áreas de vegetação ciliar estiverem preservadas, anteriormente à ocupação irregular. Um PSA nesses cenários estaria voltado à conservação de serviços ambientais naturais ainda não degradados.
A segunda opção é a aplicação (ainda sob os moldes tradicionais, como citado acima) antes que a taxa de impermeabilização do solo da bacia ultrapassasse o valor de $35 \%$. Nesse cenário, ainda há a manutenção de funções ambientais, como o escoamento subsuperficial e superficial (EPA, 2005, p. 22). Nesse caso, a adoção do PSA poderia induzir a adoção de outras técnicas ao longo da bacia que permitissem a adequação de áreas irregulares e a qualidade ambiental. Após a ultrapassagem desses parâmetros, é provável que sistemas isolados de PSA não tenham resultados significativos para o contexto geral da bacia, uma vez que as demais atividades deterioram significativamente a qualidade ambiental.

Esse é o ponto-chave da questão, o PSA não pode ser desenvolvido única e exclusivamente em sua concepção tradicional. Para alcançar os benefícios esperados, deve-se conciliá-lo com demais instrumentos de gestão e considerá-lo além de um benefício ao produtor rural que adota técnicas de conservação. Hoje, ele poderia ser aplicado para a conservação em parceria com demais instrumentos que venham garantir o desenvolvimento de serviços ambientais (como as apresentadas no Quadro 1).

Comumente, na literatura, encontra-se que o produtor rural é o principal ator quando se trata da quantidade e qualidade da conservação dos recursos hídricos. Ao mesmo tempo, as áreas urbanas, tal qual se observa no campo em estudo, são as principais destruidoras da qualidade ambiental dos recursos hídricos. Logicamente, somam-se, ainda, técnicas inadequadas nas áreas de agricultura e pecuária que acabam por contribuir para a piora ambiental de uma bacia hidrográfica. Nesse cenário, é óbvio que a esperança pela 
conservação dos recursos hídricos não deve recair unicamente sobre o produtor rural. É devido a isso que sistemas de PSA "tradicionais", ou seja, que beneficiam e abrangem unicamente produtores rurais, não têm potencial para manter a provisão de tais benefícios em um horizonte de tempo, em que haja um processo de urbanização. Nesse caso, seria conveniente ressaltar que ele só seria efetivo em uma região unicamente rural e que, com sua aplicação, evitasse o desmembramento de áreas e a expansão urbana.

Em uma bacia de manancial que apresenta área urbana e tendências de crescimento, o PSA "tradicional" encontra pequeno espaço quando trabalhado isoladamente. Para alcançar o fim principal que é a provisão de serviços ambientais relacionados à água, torna-se essencial o desenvolvimento de demais técnicas e aplicação de outros instrumentos, tais como os apresentados no Quadro 1 e que se referem à área urbana. Dessa forma, a conservação de uma bacia só ocorre com o desenvolvimento de serviços ambientais naturais e antrópicos, exemplo:

a) serviços ambientais naturais: adoção de técnicas de recuperação de APP e demais áreas de vegetação, aplicação de técnicas sustentáveis de agricultura (conservação do solo, sistema agroflorestal, agricultura orgânica);

b) serviços ambientais antrópicos: desenvolvimento em quantidade e qualidade de todos os serviços de saneamento básico, incluindo a adoção de técnicas de drenagem sustentável.

Então se deduz que, havendo o desenvolvimento de serviços ambientais além das áreas "tradicionais" de conservação (localizadas majoritariamente em área rural), também há a possibilidade de PSAs desenvolvidos em áreas urbanas, abrangendo serviços ambientais "naturais" e "antrópicos". Por exemplo, residentes da área urbana que adotam técnicas de drenagem urbana sustentável, tais como captação e aproveitamento da água da chuva, telhados verdes, calçadas permeáveis, áreas verdes em seus lotes, etc., poderiam receber incentivos financeiros (PSA ou outros instrumentos econômicos) para tal atitude, uma vez que, seguramente, eles prestam serviços ambientais no âmbito dos recursos hídricos locais. Os pequenos agricultores, cujas áreas por vezes podem estar localizadas em regiões com recursos importantes para as cidades, podem adotar técnicas de agricultura e pecuária menos ofensivas, além de proteger APPs e conservar remanescentes florestais. Isso se aplica, também, para toda a área rural. Nesse caso, suas ações promovem o desenvolvimento de serviços ambientais, passíveis de serem motivados pelo PSA.

Nessa concepção mais holística, o PSA vai além da compensação aos produtores rurais para que sejam adotadas técnicas para manejo de áreas naturais (PSA "tradicional"). O PSA pode abranger todos os esforços que promovam o desenvolvimento de serviços ambientais. Dessa forma, ele pode compensar e incentivar agricultores pela conservação de remanescentes florestais e também pelo desenvolvimento da agricultura e pecuária menos ofensivas (agricultura orgânica, sistemas agroflorestais, sistemas de tratamento de fezes de animais, etc.). Na área urbana, pode-se valorizar aqueles que promovem técnicas que influenciem na qualidade ambiental e na resiliência da cidade, atitudes que garantem o desenvolvimento de serviços ambientais relacionados aos recursos hídricos e à qualidade ambiental.

$\mathrm{Na}$ área urbana, o próprio município e o estado podem ser os prestadores de serviços 
ambientais, quando estes garantem a qualidade dos serviços de saneamento básico, por exemplo. 0 desenvolvimento da drenagem urbana sustentável também reflete o desenvolvimento de serviços ambientais. A população é agente importante nesse processo, quando adota técnicas adequadas em seu espaço que, mesmo localmente, em conjunto vem prestar serviços ambientais essenciais ao equilíbrio do meio ambiente e necessários à vida em geral. Cabe então definir de que forma o PSA poderia beneficiar esses prestadores.

A ocupação urbana disputa local com as áreas de mananciais hídricos que abastecem esses mesmos núcleos urbanos, essa é a realidade de Curitiba e de demais municípios metropolitanos, por exemplo. Seguramente, essa realidade se repete para as demais metrópoles brasileiras e possivelmente para núcleos urbanos menores também. A busca por bens e serviços ambientais apenas em regiões rurais para além da cidade é um caminho longo e não sustentável. Necessário se torna conciliar a ocupação urbana com a manutenção dos serviços ambientais para sustentação da cidade e da qualidade de vida da população que ali vive. Nesse sentido, sendo o PSA um instrumento que visa à manutenção de serviços ambientais, valorizando esforços nesse sentido, conclui-se que ele é um instrumento potencial para que mananciais hídricos urbanos não percam sua função essencial de fornecer água em quantidade e qualidade necessária à população.

O PSA seria ferramenta fundamental para garantia da valorização de serviços ambientais em uma área cujo objetivo fosse limitar o crescimento urbano visando à conservação ambiental de mananciais hídricos. Observa-se que a restrição da urbanização e de diversas outras atividades relacionadas cria uma barreira para o desenvolvimento econômico e social de um município ou região, intimidado ao lado de seus vizinhos cuja marcha ao desenvolvimento econômico e social anda em passos muito mais largos. Essa situação comprometedora poderia ser evitada com a valorização dos serviços ambientais desenvolvidos por um determinado prestador (seja ele uma pessoa, um local, uma região, etc.) cuja ferramenta básica para sua promoção pode ser o PSA e/ou demais incentivos econômicos que supram o déficit ao qual o prestador está submetido quando seu serviço não é valorizado.

A aplicação do PSA em um cenário já degradado remete à possibilidade desse instrumento ser utilizado com a finalidade de recuperação ou revitalização de serviços ambientais. Exemplo dessa possibilidade é sua utilização para incentivo de mudanças nas técnicas convencionais de agricultura e pecuária para técnicas menos ofensivas; outro exemplo seria a mudança de técnicas convencionais de drenagem para técnicas sustentáveis, além da requalificação dos serviços de saneamento básico.

A partir das constatações feitas ao longo deste trabalho e como discutido nos parágrafos anteriores, observa-se que o PSA pode ser (positivamente) um instrumento potencial para a gestão de mananciais hídricos urbanos, desde que ele seja adotado em sua concepção "holística" ou em conjunto com demais instrumentos que garantam a provisão de serviços ambientais relacionados aos recursos hídricos em uma determinada área. A questão-chave do PSA e também de toda a gestão ambiental é o desenvolvimento de serviços ambientais: havendo serviços ambientais, há a possibilidade de adoção do PSA. 


\section{Conclusão}

Este trabalho buscou estudar o PSA voltado especificamente à gestão de mananciais hídricos urbanos, considerando a problemática relacionada à escassez hídrica nos grandes centros urbanos. Ele é um instrumento ainda pouco difundido na gestão urbana, embora no Brasil ele venha sendo utilizado na gestão de recursos hídricos, principalmente com a finalidade de conservação de mananciais hídricos de grandes cidades. Seu conceito pode ser complexo e seu potencial pouco entendido atualmente, somando-se à falta de legislação nacional que estabeleça uma política de PSA.

Para estudá-lo, primeiramente foi necessário entender o que são os serviços ambientais e qual sua importância à vida humana, pois o pagamento é condicionado à existência e ao desenvolvimento de tais serviços. A partir disso, chegou-se à seguinte constatação: o equilíbrio de todo o meio ambiente (incluindo o urbano) depende do desenvolvimento de serviços ambientais. Ou seja, o desenvolvimento de serviços ambientais garante o equilíbrio ambiental, desde que esses serviços sejam voltados à manutenção das condições essenciais para a vida, incluindo as ações humanas com tal objetivo (exemplo: as estações de tratamento de esgotos, a drenagem sustentável, o tratamento de resíduos sólidos, etc.), trazendo a ideia de "serviços ambientais antrópicos".

Retomando ao tema "PSA", observa-se que o pagamento pode ser feito sempre que houver o desenvolvimento de um serviço ambiental (natural ou antrópico) essencial ao equilíbrio ambiental e do qual a sociedade se beneficia, sendo essencial à vida e passível de valoração. Nesse ponto recai a principal contribuição e sugestão deste trabalho: o desenvolvimento de um PSA inovador e holístico, em contrapartida ao tradicional, comumente observado em utilização no Brasil. O PSA tem sido subestimado e possui um potencial muito maior para a gestão ambiental das cidades, incluindo a gestão de mananciais hídricos urbanos. Ele pode ser um instrumento controlador para que atividades nocivas não sejam desenvolvidas e, também, incentivador para que boas técnicas sejam adotadas. Para isso, torna-se essencial esclarecer algumas lacunas sobre o tema:

a) o que são serviços ambientais? Em um contexto da sociedade e do ecossistema em que estamos inseridos, o que são serviços essenciais para a sustentação da vida, considerando que as cidades estão inclusas nesse meio ambiente e são um ecossistema parte de um todo maior? Estudos mais aprofundados sobre esse tema recaem sobre a ideia de serviços ambientais naturais e antrópicos;

b) como valorar os serviços ambientais de forma que eles não sejam subjugados em relação ao seu real valor para a sociedade? Este é outro ponto essencial para trazer à tona o potencial do PSA. Muitas dificuldades são encontradas para se saber o valor (monetário ou não) de um serviço ambiental, e o desafio está no desenvolvimento de estudos sobre o assunto, envolvendo uma equipe multidisciplinar, com profissionais da área ambiental, social e econômica;

c) como fundamentar uma política de PSA abrangendo todo o potencial que tal instrumento tem para a gestão urbana, rural e ambiental em todos os seus desdobramentos e conexões? Essa política deverá considerar a complexidade envolvida nos conceitos de serviços ambientais e no pagamento por tais serviços, bem como valorizar todo o potencial 
que pode estar envolvido nesse instrumento. Além disso, deve-se considerar a possibilidade de utilização do PSA como um instrumento de revitalização da qualidade ambiental e não apenas como de conservação ou manutenção.

Essas três questões levantadas acima demonstram a necessidade de aprofundamento sobre o tema, constatando-se, desde já, que o PSA possui um potencial muito maior do que aquele previsto no início desta pesquisa: ele é um instrumento potencial para a gestão de mananciais hídricos urbanos e para o equilíbrio ambiental das cidades e dos ecossistemas, uma vez que pode incentivar o desenvolvimento de diferentes tipos de serviços ambientais (naturais e antrópicos). Por fim, ressalta-se que o estudo sobre as lacunas listadas acima é uma proposta significativa para o atual e já passado momento em que a sociedade se encontra. Diante dos diversos mananciais hídricos brasileiros descartados devido à deterioração ambiental, observa-se que o PSA poderia evitar tais cenários degradantes se concebido adequadamente, visando a sua finalidade principal: conservação e manutenção de serviços ambientais. Uma vez degradada, a principal conclusão deste estudo pode ser expressa por meio de uma pergunta: quanto custa para se fazer um novo manancial hídrico? Essa questão remete à necessidade de adaptação da cidade aos recursos hídricos em que medidas a priori ao processo de urbanização seriam muito mais eficazes e simples para a manutenção de um manancial e de toda uma cidade saudável.

\section{[I] https://orcid.org/0000-0002-3571-5685}

Pontifícia Universidade Católica do Paraná, Escola de Arquitetura e Design, Programa de Pós-Graduação em Gestão Urbana. Curitiba, PR/Brasil.

anapaulaschim@gmail.com

\section{[II] https://orcid.org/0000-0001-7982-5803}

Pontifícia Universidade Católica do Paraná, Escola de Arquitetura e Design, Programa de Pós-Graduação em Gestão Urbana. Curitiba, PR/Brasil.

carlos.garcias@pucpr.br

\section{Referências}

ALTMANN, Alexandre (2012). Pagamento por serviços ambientais como instrumento de incentivo para os catadores de materiais recicláveis no brasil. Revista de Direito Ambiental, n. 68. São Paulo, Editora Revista dos Tribunais, outubro/dezembro, pp. 307-328. Disponível em: http:// www.planetaverde.org/arquivos/biblioteca/arquivo_20131207155702_7421.pdf. Acesso em: 21 out 2017. 
ANA - Agência Nacional de Águas (2020). Programa Produtor de Água. Disponível em: <https://www. ana.gov.br/programas-e-projetos/programa-produtor-de-agua/projetos $>$. Acesso em: 28 jan 2020.

ANDREOLI, C. V.; HOPPEN, C.; PEGORINI, E. S. e DALARMI, O. (2003). “A crise da água e os mananciais de abastecimento - a disponibilidade de água na RM Curitiba". In: ANDREOLI, C. V. Mananciais de abastecimento: planejamento e gestão. Curitiba, Sanepar e Finep, cap. 2, pp. 33-84.

BRASIL (1997). Lei federal n. 9.433, de 8 de janeiro de 1997. Institui a Política Nacional de Recursos Hídricos, cria o Sistema Nacional de Gerenciamento de Recursos Hídricos. Publicado no Diário Oficial da União de 9 de janeiro de 1997. Disponível em: <http://www.planalto.gov.br/ccivil_03/ leis/L9433.htm>. Acesso em: 10 out 2016.

(2009). Projeto de lei n. 5.487 de 2009. Institui a Política Nacional dos Serviços Ambientais, o Programa Federal de Pagamento por Serviços Ambientais, estabelece formas de controle e financiamento desse Programa, e dá outras providências. Câmara dos Deputados, 2009. Disponível em: <http://www.camara.gov.br/proposicoesWeb/fichadetramitacao?idProposic ao $=43994>$. Acesso em: 20 set 2017.

(2010). Lei federal n. 12.305, de 2 de agosto de 2010. Institui o Sistema Nacional de Resíduos Sólidos e dá outras providências. Publicado no Diário Oficial da União de 3 de agosto de 2010. Disponível em: <http://www.planalto.gov.br/ccivil_03/_ato2007-2010/2010/lei/l12305.htm>. Acesso em: 20 abr 2017.

(2012). Lei federal n. 12.651, de 25 de maio de 2012. Dispõe sobre a proteção da vegetação nativa e dá outras providências. Publicado no Diário Oficial da União de 28 de maio de 2012. Disponível em:<http://www.planalto.gov.br/ccivil_03/_ato2011-2014/2012/lei/l12651.htm>. Acesso em: 14 maio 2017.

CHICHILNISKY, G. e HEAL, G. (1998). Economic returns from the biosphere - commentary. Nature, v. 391, n. 6668, pp. 629-630.

CIDREIRA, L. E. (2016). Pagamento por serviços ambientais como instrumento para a gestão das águas em ambientes urbanos. Dissertação de Mestrado. Curitiba, Pontifícia Universidade Católica do Paraná. Disponível em: <http://www.pucpr.br/posgraduacao/gestaourbana/dissertacoes.php>. Acesso em: 20 out 2016.

ENGEL, S.; PAGIOLA, S. e WUNDER, S. (2008). Designing payments for environmental services in theory and practice: an overview of the issues. Ecological Economics, v. 65, n. 4, pp. 663-674.

EPA - Environmental Protection Agency (2005). National Management Measures to Control Nonpoint Source Pollution from Urban Areas. Washington, DC. Disponível em: <http://www.epa.gov/ owow/nps/urbanmm/pdf/urban_guidance.pdf>. Acesso em: 29 maio 2017.

FAO - Food and Agriculture Organization of the United Nations (2003). Review of world water resources by country. Water Reports, n. 23. Disponível em: <http://www.fao.org/docrep/005/ y4473e/y4473e00.htm\#Contents>. Acesso em: 14 abr 2016.

GUEDES, F. B. e SEHUSEN, S. E. (orgs.) (2011). Pagamentos por Serviços Ambientais na Mata Atlântica: lições aprendidas e desafios. Brasília, MMA.

KFOURI, A. e FAVERO, F. (2011). Projeto conservador das águas passo a passo: uma descrição didática sobre o desenvolvimento da primeira experiência de pagamento por uma prefeitura municipal no Brasil. Brasília, The Nature Conservancy do Brasil. 
MEA - Millennium Ecosystem Assessment (2005). Ecosystems and Human Well-Being: synthesis. World Resource Institute. Washington, Island Press. Disponível em:<http://www.millenniumassessment. org/en/Synthesis.html>. Acesso em: 18 abr 2016.

MENDES, G. de S. e FREIRIA, R. C. (2017). Pagamento por serviços ambientais: o estado da arte da política brasileira. Âmbito Jurídico. Rio Grande. Disponível em: <http://ambito-juridico.com.br/ site/?n_link=revista_artigos_leitura\&artigo_id=18841>. Acesso em: 6 abr 2017.

MMA - Ministério de Meio Ambiente (2011). Plano Nacional de Recursos Hídricos: prioridades 20122015 (primeira revisão). Brasília: Ministério do Meio Ambiente. Disponível em: <http://www.mma. gov.br/publicacoes/agua/category/42-recursos-hidricos?start=40>. Acesso em: 29 maio 2017.

PARANÁ (2012). Lei Estadual n. 17.134, de 25 de abril. Institui o Pagamento por Serviços Ambientais, em especial os prestados pela Conservação da Biodiversidade, integrante do Programa Bioclima Paraná, bem como dispõe sobre o biocrédito. Publicado no Diário Oficial do Estado do Paraná de 25 de abril de 2012. Disponível em: <http://www.legislacao.pr.gov.br/legislacao/pesquisarAto. do?action=exibir \&codAto=67272\&indice=1\&totalRegistros=1>. Acesso em: 24 out 2016.

SANEPAR - Companhia Paranaense de Saneamento (2013). Plano Diretor do Sistema de Abastecimento de Água Integrado de Curitiba e Região Metropolitana. Curitiba, Sanepar.

TOZZI, Rodrigo Henrique Branquinho Barboza (2015). O PSA urbano como manifestação do poder da polícia ambiental do município. Revista Síntese Direito Ambiental, v. 23, pp. 13-26. Disponível em: <http://www.lex.com.br/doutrina_26094023_O_PSA_URBANO_COMO_MANIFESTACAO_DO_ PODER_DE_POLICIA_AMBIENTAL_DO_MUNICIPIO.aspx>. Acesso em: 21 out 2017.

WUNDER, S. (2005). Payments for Environmental Services: Some Nuts and Bolts. Indonesia: Center for International Forestry Research. Disponível em: <http://theredddesk.org/sites/default/files/ resources/pdf/2012/payment-ecosystem-services-02.pdf>. Acesso em: 22 abr 2014.

(2015). Revisiting the concept of payments for environmental services. Ecological Economics, v. 117, pp. 234-243. Disponível em: <http://dx.doi.org/10.1016/j.ecolecon.2014.08.016>. Acesso em: 1ㅇago 2016.

Texto recebido em 18/jun/2018

Texto aprovado em 21/out/2018 